\title{
A EDUCAÇÃO FÍSICA E A ESCOLA: OU A EDUCAÇÃO FÍSICA NA ESCOLA
}

\author{
MIRANDA, Márcia ${ }^{1}$ \\ ANTUNES, Marcelo Moreira ${ }^{2}$
}

\section{RESUMO}

Tendo em vista as conformações da escola contemporânea e das disciplinas curriculares que compõem esse cenário de ensino, a educação física também influencia e é influenciada por esse contexto. $O$ presente texto se coloca na perspectiva de refletir sobre a educação física inserida na educação básica como elemento dialógico com as diferentes disciplinas para a formação do corpo discente de forma integral e preparado para o exercício pleno da cidadania. $O$ texto se propõe a apresentar uma reflexão sobre o pensamento da educação física desenvolvida no CAp-UERJ a partir da perspectiva de algumas obras, entendendo que é ampla a abrangência do trabalho em educação física escolar.

PalaVRAS-CHAVE: Educação Física Escolar - Cidadania - Função pedagógica.

\section{ABSTRACT}

In the view of the fact that the structure of contemporary school and mandatory disciplines which it comprises this teaching scenario, the physical education can both influence and be influenced by this context. The presented text conveys a perspective of reflecting the physical education as a dialogical element between different disciplines for integral development of students and preparing them for full exercise of citizenship. The text aims to present at the CAp-UERJ from the perspective of some works, understanding that physical education has a broad scope of work.

KeYwORDS: School Physical Education - Citizenship - Pedagogical function.

\footnotetext{
${ }^{1}$ Professora Assistente do Instituto de Aplicação Fernando Rodrigues da Silveira (CAp-UERJ) e do Centro Universitário Augusto Motta (UNISUAM). Email: mirandamarcia@uol.com.br

2 Professor Adjunto do Instituto de Aplicação Fernando Rodrigues da Silveira (CAp-UERJ) e do curso de pósgraduação em educação física escolar da Universidade Federal Fluminense (UFF). Email: antunesmm@gmail.com
} 
e-Mosaicos - Revista Multidisciplinar de Ensino, Pesquisa, Extensão e Cultura do Instituto de Aplicação Fernando Rodrigues da Silveira (CAp-UERJ)

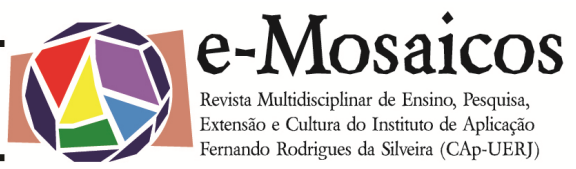

\section{APRESENTAÇÃo}

No cenário contemporâneo, temos visto recorrentes discussões sobre a Educação, sobre os problemas da educação pública no nosso país, envolvendo tentativas de diagnóstico, que associam o problema à sucessão de governos ineptos, à falta de continuidade das políticas, à insuficiência dos investimentos públicos na educação ou à má gestão dos recursos disponíveis e por fim, à baixa valorização dos profissionais da educação. Sobre esse aspecto, Aranha (2006) sinaliza que ao longo da história brasileira muitos projetos e programas governamentais visaram 0 desenvolvimento de uma política pública para a educação. Entretanto, essas políticas sempre priorizavam ao atendimento de interesses específicos e não às demandas da população e dos educandos. No que tange a educação física escolar, o processo não foi diferente. Historicamente a educação física atendeu a interesses muito particulares e as políticas públicas implantavam modelos que destoavam dos interesses da população. A especialização da educação física era a tônica, enfatizando aspectos biológicos e esportivos de alto rendimento (BRACHT; ALMEIDA, 2003).

Almeida e Gutierrez (2005) ainda destacam o controle social como um modelo de utilização da escola, da educação e também da educação física na sociedade brasileira. Os governos desenvolviam programas criados a partir de modelos preexistentes de cunho comportamentalista, com um único objetivo: controlar os grupos sociais que porventura resistissem às políticas públicas mais amplas. Principalmente as que influenciavam a educação brasileira.

Diante de todo esse quadro contextual, na maioria das vezes desacreditada, queremos, nesse artigo, destacar que acreditamos no valor da Educação Física dentro da escola como ferramenta educativa, mostrando seu valor na formação de um cidadão crítico e consciente, e confe- rimos a possibilidade do diálogo dessa disciplina com as outras áreas de conhecimento da escola, contribuindo para a formação integral do aluno.

\section{UMA REFLEX̃̃o SOBRe A EdUCAÇÃo FísICA ESCOLAR}

Em primeiro lugar, é preciso acreditar que a Educação Física não se limita a ensinar aspectos técnicos das modalidades esportivas, mas lida com a conscientização dos jovens, fazendo-os pensar sobre o que é viver em sociedade, entendendo o valor do respeito às diferenças e limites do próximo, estimulando as aplicações de seus direitos como cidadãos. A oportunidade de conhecer e aprender as atividades físicas na escola proporciona um aprendizado único, que tem a intenção de transportar as lições aprendidas no espaço escolar à vida cotidiana futura. De acordo com Soares (1992), não se deve trabalhar o esporte como conteúdo hegemônico, pois isso poderia restringir as demais experiências que devem ser valorizadas nesse espaço, como os componentes da cultura corporal, as brincadeiras e jogos, as ginásticas, as lutas, as danças, atividades essas que agregam valores éticos, de respeito, diálogo e cooperação. Percebe-se, nos dias atuais, uma insensibilidade pelo próximo, inexiste o olhar para o outro, o cuidado com o próximo, o respeito às diferenças. Valores como esses estão sendo esquecidos e o autocentrismo está tomando conta das pessoas. Para Giddens (2002), a conformação da modernidade tardia coloca os sujeitos em uma condição de extremo individualismo, fragmentando sua identidade frente aos diferentes contextos sociais em que se apresenta. $A$ insensibilidade frente ao outro surge dessa falta de eixo norteador, da ausência do norte que conduz para um conviver social. Hall (2006) também salienta os efeitos do que ele chama de Pós-Modernidade. Nesse cenário social, onde as tessituras se desfazem com grande intensidade, onde as redes sociais 
e-Mosaicos - Revista Multidisciplinar de Ensino, Pesquisa, Extensão e Cultura do Instituto de Aplicação Fernando Rodrigues da Silveira (CAp-UERJ)

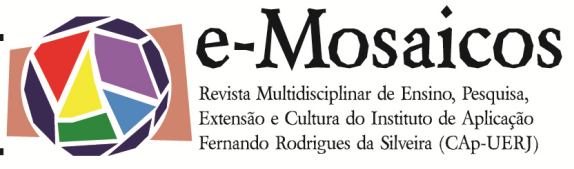

se fragilizam, o sujeito cada vez mais se torna um elemento autocentrado e individualista. A Educação Física tem muito a contribuir nesse sentido, fazendo os alunos entenderem que o outro faz parte da minha prática, que o outro é necessário para o meu crescimento individual, pois esse conteúdo escolar se estabelece nas relações do indivíduo com o outro e com o grupo no qual está inserido.

Nesse sentido, muitos autores defendem a ideia que a Educação Física deve favorecer o pensamento crítico e as soluções de problemas. Na visão críticoemancipatória de Kunz (1994), o autor propõe uma Educação Física Escolar que seja pautada na comunicação, em que o educando terá que, por meio da linguagem, fazer uma autorreflexão das práticas de atividades físicas. Nessa perspectiva, desenvolve-se a capacidade de saberfazer, mas também, saber sobre esse saber, entendendo o sentido e o significado do mover-se. Sobre isso, Soares (1992) traz a resolução de problemas como sendo uma forma de trabalhar com os educandos os conflitos sociopolíticos atuais, sem que essa seja uma ação de doutrinamento, e sim de leitura da realidade, porém, com uma percepção de que a estrutura social se organiza em forma de classes sociais baseadas nas relações de produção de capital e do trabalho. Destaca-se ainda o pensamento de Betti (1994), que entende a função pedagógica da Educação Física em integrar os alunos do Ensino Fundamental e Médio no mundo da cultura corporal de movimento, formando um cidadão capaz de usufruir, participar, produzir, reproduzir e transformar as suas manifestações culturais. E por fim, destaca-se 0 pensamento de Daolio (2005), que defende que os alunos precisam considerar suas manifestações culturais como produto de suas ações humanas e processo contínuo de reprodução e transformação dessas ações durante a vida. Os conteúdos transmitidos nas aulas de Educação Física devem levar o educando a libertar-se dos moldes e padrões dominantes existentes, procurando significados para ampliar e aprofundar a compreensão do real vivido, persistindo na reflexão sobre a realidade social que os envolve. Além disso, esses conteúdos devem favorecer o desenvolvimento de uma visão crítica sobre os padrões de comportamento, de consumo e de estética que são incutidos como fundamentais para a felicidade na sociedade contemporânea.

Essa abordagem crítica da educação física se realiza a partir de uma cognição mais ativa, excitada e mais incisiva. Assim, pressupondo algumas práticas, como analisar a significância das práticas corporais diversas para o processo de formação continuada do homem, refletir sobre as implicações positivas e negativas dessas práticas nas perspectivas biológica, intelectual e sociocultural, relacionar criticamente os conflitos e contradições que surgem nas as aulas similares àquelas manifestadas no contexto social, identificar e analisar, a partir de um ponto de vista histórico, os sentidos e os valores sociais, morais, éticos e estéticos subjacentes à cultura corporal (RESENDE; SOARES, 1996).

E assim, a partir dessa perspectiva de Educação Física, defendemos a importância do diálogo com as outras disciplinas. O mundo moderno não se contenta com seres treinados, que dominam habilidades pela via da domesticação copiada. Exige, sim, capacidade de 'aprender a aprender', saber pensar e construir conhecimentos com qualidade. (DEMO, 1994). Dessa forma, quando se acredita que não há transmissão de conhecimentos, se este não se der por meio de um processo de reconstrução dos significados, se entende o processo educacional como uma concreta construção simultânea desses conhecimentos, formada pelo diálogo entre as disciplinas, pela construção dos conteúdos e significados em rede. Formar um indivíduo crítico e capaz de todas essas análises, significa colocá-lo em reflexão em 
e-Mosaicos - Revista Multidisciplinar de Ensino, Pesquisa, Extensão e Cultura do Instituto de Aplicação Fernando Rodrigues da Silveira (CAp-UERJ)

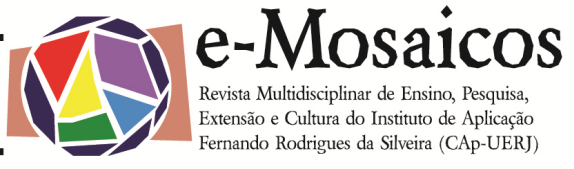

todas as disciplinas escolares, possibilitando, assim, um diálogo social diversificado, embasado em todos os conhecimentos e reflexões produzidas no ambiente escolar.

Sobre o conhecimento e sua estruturação para o ensinar formal, escolar, Goodson (2008) alerta que a construção de um currículo se dá por meio de disputas que, em sua maioria, não estão ligadas aos interesses da maioria, mas sim de um grupo dominante que controla os processos decisórios. Portanto, o refletir sobre o conhecimento deve incluir todos os atores que fazem parte do processo de ensino aprendizagem, o que considera principalmente os alunos e seus interesses no centro dessa dinâmica.

Desse modo, a escola se constitui como um espaço de diálogo entre os diferentes atores que a compõem. Libâneo (2003) e Luckesi (2005) corroboram com esse pensamento quando afirmam que o diálogo na escola é ponto de partida para a mediação do enfrentamento com a realidade. É fundamental para a construção das possibilidades de transformações sociais em uma perspectiva crítica. E, para isso, todos os sujeitos envolvidos no processo educativo devem se envolver nesse trabalho responsável e comprometido com a sociedade.

Podemos traçar um paralelo entre o PCN (BRASIL, 1998), que entende a Educação Física como um componente curricular que introduz e integra os alunos na cultura corporal de movimento, formando cidadão críticos, delimitando a cidadania como eixo norteador e o papel da Educação Física na formação dos alunos. É nosso papel formar alunos capazes de participar de atividades corporais, adotando atitudes de respeito mútuo, dignidade e solidariedade; capazes de reconhecer-se como sujeito integrante do ambiente, adotando hábitos saudáveis e relacionando-os com a saúde; capaz de conhecer a diversidade de padrões de beleza e de desempenho nos diferentes grupos sociais, anali- sando criticamente os padrões divulgados pela mídia; capazes de reivindicar, organizar e interferir no espaço de forma autônoma, reivindicando espaços apropriados para a prática de atividade física.

Ainda no sentido de contribuir com essa discussão, o PCN indica algumas competências e habilidades que devem ser desenvolvidas pelos alunos durante o processo de ensino-aprendizagem, Isso quer dizer que as ações pedagógicas dos professores de Educação Física são diversas e devem buscar desenvolver nos alunos determinadas competências e habilidades, como por exemplo, demonstrar autonomia na elaboração de atividades corporais, assumir uma postura ativa na prática das atividades físicas, participar de atividades em grandes e pequenos grupos, compreender o funcionamento do organismo humano, desenvolver noções conceituadas de esforço, intensidade e frequência, aplicando-os nas suas práticas corporais, refletir sobre as informações específicas da cultura corporal e compreender sobre suas diferentes manifestações.

\section{CONSIDERAÇÕES FINAIS}

Diante dessa argumentação, acreditamos serem necessárias outras alternativas didáticas do professor de Educação Física na educação básica, diferentes das padronizadas aulas práticas de movimentos corporais. $O$ aluno não pode, ao final de todos os anos de escolarização, ter a triste constatação de que não aprendeu conteúdo algum sobre a disciplina, ficando restrito a movimentos corporais, sem que seja trabalhado um mínimo de autonomia no aluno. Ou seja, ao final dos seus doze anos de educação básica, o aluno não tem a noção básica sobre suas necessidades orgânicas durante os exercícios, não conhece seu corpo, não reflete sobre questões de saúde e lazer e outros conhecimentos pertinentes à disciplina para a formação de um indivíduo atuante na sociedade. Não estamos aqui negando que é 
o movimento corporal que confere especificidade à Educação Física Escolar, porém, não é qualquer movimento institucionalizado, reproduzido, estereotipado, esvaziado e acabado. Trata-se do movimento humano com sentido e significado aferido pelo contexto sócio-histórico-cultural em que é produzido. Estamos falando de movimento que expressa e representa uma cultura, que comunica seus sentidos na realidade em que se vive e que se dá no interior de uma manifestação cultural, que abarca conteúdos primordiais. Talvez essa 'falta de conteúdo' seja um dos motivos mais latentes para a falta de legitimação da Educação Física escolar dentro da própria comunidade escolar.

Finalizamos, então, reforçando a ideia de que, as ações pedagógicas da Educação Física devem ser direcionadas para o objetivo de instrumentalizar o aluno por meio da aquisição de uma bagagem de conhecimentos que lhe permita atuar de forma eficaz sobre a manutenção de sua saúde, a gerência de seus momentos de lazer e a aquisição de um vocabulário motor que possibilite um diálogo social diversificado. Dito de outra forma, desejamos adultos ativos, corresponsáveis no processo de estudo e ampliação das diversas práticas corporais.

\section{REFERÊNCIAS BIBLIOGRÁFICAS}

ALMEIDA, M. A. B.; GUTIERREZ, G. L. O lazer no Brasil: do NacionalDesenvolvimentismo a Globalização. Conexões, Campinas, v.3, n.1, p.36-57, 2005.

ARANHA, M. L. A. História da educação e da pedagogia: geral e Brasil. 3ed. São Paulo: Moderna, 2006.

BETTI, M. Valores e finalidades na educação física escolar: uma concepção sistêmica. Revista Bras. Cienc. Esporte, Santa Maria, vol.16, n.1, pp. 14-21.
BRACHT, V.; ALMEIDA, F. Q. A política do esporte escolar no Brasil: a pseudovalorização da educação física. Rev. Bras. Cienc. Esporte, Campinas, v.24, n.3, p.87101, maio, 2003.

DAOLIO, J. Educação Físíca e o Conceito de Cultura. São Paulo: Autores Associados, 2005.

DEMO, P. Política Social, Educação e Cidadania. Campinas, SP: papiros, 1994.

GIDDENS, A. Modernidade e identidade. Rio de Janeiro: Jorge Zahar, 2002.

GOODSON, I. F. Currículo: teoria e história. Petrópolis: Vozes, 2008.

HALL, S. A identidade cultural na pósmodernidade. 11ed. Rio de Janeiro: DP\&A, 2006.

KUNZ, E. Didática da Educação Física. Campinas, SP: Unijuí, 1994.

LIBÂNEO, José Carlos. $A$ escola com que sonhamos é aquela que assegura a todos a formação cultural e científica para toda a vida pessoal, profissional e cidadã. In: COSTA, Marisa Vorraber (org.). A escola tem futuro? Rio de Janeiro: DP\&A, 2003.

LUCKESI, C. Filosofia da educação. São Paulo: Cortez, 2005.

RESENDE, H. G; SOARES, A. J. G. Conhecimento e especificidade da educação física escolar na perspectiva da cultura corporal. Revista Paulista de Educação Física, São Paulo, 1996.

SOARES, C. L. et al. Metodologia do Ensino de Educação Física. São Paulo: Cortez, 1992. 